\title{
INTERAÇÕES E ALTERIDADE NAS APROPRIAÇÕES DE REDES SOCIAIS E GAMES: UM ESTUDO EM LAN HOUSE POPULAR
}

\author{
Carla Barros ${ }^{1}$
}

\section{Introdução}

O objetivo do artigo $^{2}$ é analisar os sentidos da navegação na Internet junto a um grupo pertencente às camadas populares, a partir de um trabalho de campo etnográfico realizado em lan houses localizadas em uma comunidade na cidade do Rio de Janeiro. Procurou-se no estudo compreender de que modo se constitui a sociabilidade em tais espaços, investigando a adesão a redes sociais e o consumo de produtos culturais como games online.

Adotando a perspectiva de Miller e Slater (2000), não se trata apenas de falar em "usos" e "efeitos" do novo meio, mas de olhar como membros de uma cultura específica se vêem no ambiente virtual e moldam o meio segundo sua própria imagem. $\mathrm{O}$ trabalho alia-se, assim, a estudos como o de Gomes (2007), que ao analisar as fanarts - produção de imagens e narrativas ficcionais por parte de fãs de produtos midiáticos como séries de TV e filmes cultuados - mostra como estas se constituem em redes de sociabilidade criadas a partir da lógica da dádiva, revelando seu caráter de forte interação e troca social. Em um plano mais amplo, através da observação sobre a adesão a redes sociais entre diferentes grupos, o artigo busca, ainda, uma reflexão sobre a construção da alteridade no universo virtual.

O trabalho de campo etnográfico foi desenvolvido durante os anos de 2009 e 2010 na favela ${ }^{3}$ do Rocha ${ }^{4}$, localizada na Zona Sul da cidade do Rio de Janeiro. Hoje, estima-se que o Rocha tenha cerca de 4.000 moradores, bem distante do "gigantismo" de outras favelas da cidade como a da Rocinha. Existe na comunidade um relativo fluxo de turistas estrangeiros promovido em parte pelo trabalho da agência Favela Tour, que

\footnotetext{
${ }^{1}$ Universidade Federal Fluminense e Escola Superior de Propaganda e Marketing (RJ), Brasil.

${ }^{2} \mathrm{O}$ artigo apresenta resultados de uma pesquisa apoiada pelo Centro de Altos Estudos em Propaganda e Marketing (CAEPM) da ESPM.

${ }^{3}$ A denominação "favela" não foi empregada pelos moradores nos primeiros contatos com o grupo; eles se referiam ao local como uma "comunidade". Em contatos posteriores, surgiu o termo "favelinha", para denominar a localidade. Vale lembrar que o termo "favela" costuma ter uma conotação bastante negativa, quando associada às idéias de "caos", "sujeira", "desordem", "pobreza" e "violência". Para uma discussão mais ampla sobre as representações sociais relacionadas a "favela" e "comunidade", ver Alícia Valladares (2005) e Patrícia Birman (2008).

${ }^{4} \mathrm{O}$ nome da localidade, das lan houses e dos informantes são fictícios, como modo de preservar o anonimato.
} 
promove passeios turísticos ao local para conhecer a favela "por dentro" - o que inclui uma visita a projetos sociais e um tour pelo interior da favela, com paradas em lugares como um "local buteco" (www.favelatour.com.br) - e também pelo programa de turismo Favela Receptiva, onde famílias da comunidade oferecem quartos para hospedagem, convidando os visitantes a "um contato direto" com o dia-a-dia de uma "charmosa" comunidade de baixa renda, como aparece em seu site (www.favelareceptiva.com).

\section{Sociabilidade e navegações coletivas em lan houses}

A favela do Rocha tem duas lans e as navegações mais habituais nestes espaços ocorrem nas redes sociais, com destaque absoluto para o Orkut e o MSN (para ambos os gêneros), e no universo dos games (especialmente para o gênero masculino). Os meninos costumam permanecer pelo menos uma hora conectados, se ocupando na maior parte com os games e dedicando um tempo menor para a navegação no Orkut e MSN. As meninas costumam ficar bem menos tempo online; em geral, até meia hora conseguem navegar com o objetivo de alimentar suas redes de relacionamentos. $\mathrm{O}$ Orkut reina absoluto na preferência local entre ambos os gêneros e variadas faixas etárias, chamando a atenção o seu enorme grau de difusão e prestígio entre os informantes.

Para além da onipresença do Orkut, as duas lans da comunidade têm diferentes atrativos para seu público. A lan Conecta fica na rua principal, localizada nos "limites" da favela, e é especializada em games relacionados ao universo de RPG online; nela, a "febre" - expressão usada por atendentes e freqüentadores das lans - é o jogo World of Warcraft, um dos mais populares do mundo, com mais de 12 milhões de jogadores pagantes segundo dados do seu fabricante Blizzard Entertainment ${ }^{5}$. Trata-se de um universo de ação e aventura com inspiração medieval que se passa no mundo fantástico de Azeroth, introduzido no primeiro jogo da série, Warcraft: Orcs \& Humans, de 1994. O World of Warcraft ou WoW (apelido dado pelos fãs do jogo e como passo a me referir) faz parte de uma categoria denominada MMORPG - Massive Multiplayer Online Role-Playing Game ou Multi massive online Role-Playing Game - que são jogos online e em massa para múltiplos jogadores, onde personagens são criados no mundo virtual, seguindo a inspiração nos tradicionais jogos de estratégia de RPG. Já na lan

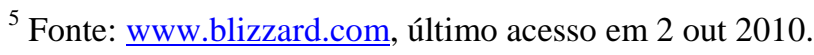


Speed, situada no meio das ruelas da comunidade, as atrações principais são o "violento" Counter-Strike e o jogo de corrida de carros Need for Speed.

Simmel (1983), em seu trabalho clássico, apresenta uma abordagem formalista da sociabilidade - um dos modos de "sociação" - onde as partes estabeleceriam relações tecidas pela cordialidade e amabilidade. Sua peculiaridade seria o fato de apresentar-se livre de conteúdos, autônoma, como uma forma de convivência com o outro e para o outro. Aqui o importante é estabelecer laços, já que o fim é a própria relação. Sem interesses práticos, a sociabilidade teria como marca a interação lúdica, onde o prazer de um depende do outro. Esta noção, para Simmel, prevê uma relação entre iguais onde a simetria prevalece, mesmo que possa haver diferenciações entre os sujeitos em outros contextos. O modo como a sociabilidade se expressa no trabalho de campo realizado será comentado a seguir.

A circulação de pessoas nas lans é grande durante todo o dia - uns passam apenas para ver o que há, quem está jogando, conversar um pouco e, quando é possível, voltar mais tarde. Não necessariamente entra-se na lan para acessar a Internet; muitos vão apenas para encontrar os outros, em um repetido ritual de sociabilidade - entre os jovens, é "de lei” dar uma passada por lá. Vários freqüentadores, por outro lado, têm computador em casa, mas preferem ir à lan para fazer um programa em grupo, seja para jogar em rede ou mesmo acessar o Orkut ao mesmo tempo em que os amigos também navegam no site.

O ambiente nas lan houses é de muita conversa e brincadeiras, devido à importância das atividades lúdicas nesses espaços, como jogos e músicas. Em lans como a Conecta, onde a presença dos jogos de estratégia online como o WoW é muito grande, o espaço fica fortemente marcado pela sociabilidade juvenil masculina, já que as meninas se interessam bem menos por este tipo de diversão. Os freqüentadores vivenciam o espaço da lan como um clube local (Barros, 2009), onde se exercita a sociabilidade em atividades lúdicas compartilhadas.

A média de idade dos jogadores no local - meninos por volta dos oito anos já começam a se familiarizar com o ambiente do jogo, se estendendo o interesse até a faixa dos 25 anos, aproximadamente - é bem menor do que a média mundial, que é de 28 anos, segundo dados da Blizzard. Isso se deve, em parte, ao fato de o WoW ser um jogo pago e nas lan houses populares, em geral, o servidor ser "pirata", o que facilita a participação dos mais jovens. 
No contexto estudado, observa-se uma aprendizagem do jogo através de um forte compartilhamento coletivo. O uso dos computadores na lan chama atenção em um aspecto específico - além dos usuários estarem conectados e interagirem com outros jogadores online, existe uma grande interação com as outras pessoas que estão no ambiente físico. Os jovens, estejam de frente ao computador ou não, se comunicam intensamente trocando "dicas" sobre as melhores estratégias e ações a serem tomadas na batalha. O "ensinamento" é passado de alguém que tenha mais expertise no jogo que os outros, papel que é tomado alternadamente por múltiplos atores - os atendentes da lan e os jogadores mais experientes. Acontece, em vários momentos, da navegação ser realmente compartilhada, quando alguém toma o mouse de quem está à frente do computador e joga durante um certo tempo, ou quando pede ajuda, como em uma cena observada: "Kiko, vem aqui porque os poderes não estão aparecendo". Kiko se aproxima, pega o mouse e resolve o "problema", devolvendo depois o controle do jogo ao colega. $\mathrm{O}$ aprendizado gira em torno de dicas sobre a lógica geral do WoW, seu passo a passo, as melhores estratégias a serem adotadas, o significado de palavras e expressões em inglês e ainda a melhor forma de manusear o mouse e os teclados, a fim de se alcançar maior agilidade nos combates.

Podem ser duas, três ou quatro pessoas ao redor de um mesmo computador, com uma "oficialmente" protagonizando a aventura, outra, de maior expertise, tomando o mouse em alguns momentos para avançar nas etapas, e terceiras fazendo comentários sobre o jogo ou simplesmente "zoando". De certo modo, existe aqui um contraponto com a idéia original de personal computer - no ambiente da lan house encontram-se máquinas coletivas, funcionando de um modo colaborativo, como um "computador pessoal compartilhado".

Pensando no jogo "jogado" sob um ângulo mais amplo, temos no mesmo ambiente multiplayer online configurações de players diversas - uma pessoa em um processo imersivo individual que joga com multiplayeres online; outra pessoa que além dos jogadores no ambiente virtual está imersa na lan em um processo em que se alterna ação individual e coletiva.

Algumas palavras surgidas no jogo são incorporadas ao vocabulário, como "nubie" ("iniciante") ou "quitar" (abandonar, desistir do jogo). No ambiente virtual, os mais experientes fogem dos "nubies e dos "quiters" nas jornadas do WoW; na palavra de um deles: "aqui só tem "pró"”("profissional”, experiente no jogo), "sem quiter nem nubie". Tanto no ambiente de sociabilidade encontrado na lan house quanto no virtual, 
surge uma diferenciação de status - na lan os jogadores com mais expertise se destacam e têm maior prestígio, circulando com desenvoltura e colocando em prática seus conhecimentos no "jogo coletivo"; no espaço propriamente virtual, onde toda a comunidade WoW interage, os mais experientes se distanciam dos quiter e nubie, formando o grupo "seleto" dos pró.

\section{Adesão ao Orkut}

A "alfabetização digital" nas camadas populares no Brasil tem sido feita, em grande parte, através da adesão ao Orkut (Spence, 2007). É através dessa rede social que a maior parte das pessoas, especialmente no universo dos grupos populares, tem seu primeiro contato com a internet no país ${ }^{6}$. Para estes segmentos sociais, estar no Orkut é um modo de estar no mundo. Quando cheguei pela primeira vez a uma das favelas onde desenvolvo pesquisa, um menino de 5 anos, filho do rapaz que me levava a conhecer a comunidade, perguntou para o pai: "Ela tem Orkut?" Esse mesmo menino, ainda não alfabetizado, sabia entrar nesta rede social e era ajudado por outras pessoas na lan house local quando queria incluir algum material novo na sua página.Nas palavras do pai: "Ele não sabe ler, mas sabe entrar no Orkut. As meninas [amigas mais velhas] colocam as fotos pra ele".

A “iniciação" no universo do Orkut é feita preferencialmente de duas maneiras através da ajuda de um amigo ou familiar mais jovem, ou ainda, contando com o auxílio dos atendentes de lan houses. Sua interface amigável em comparação a outras redes também contribui para a adesão maciça.

Muitas ONGs e programas de "inclusão digital" do governo têm políticas restritivas ao acesso ao Orkut - e também aos games - em seus espaços, o que leva a um significativo desinteresse das populações locais em freqüentar os lugares de acesso gratuito à Internet disponíveis em seus bairros, enquanto as lan houses se mantém com um movimento frenético. É possível se fazer um contraponto entre as ONGs e os

\footnotetext{
${ }^{6}$ O Brasil é um dos países com maior adoção de redes sociais em todo o mundo, liderando a lista de países com mais usuários que visitam redes sociais, em proporção ao número total de internautas. $\mathrm{O}$ Orkut foi um dos sites que ajudou a popularizar as redes sociais no Brasil. O Google lançou a versão brasileira do site em 2004 e, em setembro de 2005, metade dos brasileiros ativos na internet já havia se conectado ao Orkut; em 2010, cerca de 70\% dos usuários da Internet no Brasil navegam no site (dados de junho de 2010). O Facebook, embora amplamente disseminado pelo mundo, ainda mostra números tímidos no Brasil - 26\% dos usuários ativos da Internet no Brasil em junho de 2010 - se encontrando atualmente em fase de franca expansão no país. (Fonte: Ibope Nielsen online, disponível em www.ibope.com.br)
} 
telecentros (locais de acesso gratuito à Internet, patrocinados pelo Estado), de um lado, e o ambiente de alta sociabilidade encontrado nas lans, de outro. Nos primeiros, percebe-se uma dicotomia entre "educação" e "entretenimento", vistos como antagônicos. O segundo termo é algo até tolerado, mas sempre controlado. Os coordenadores destes espaços gratuitos, via de regra, mostram a preocupação de controlar ou eliminar o acesso aos conteúdos lúdicos disponíveis na Internet, vistos como perturbadores dos "verdadeiros" processos educacionais.

O Orkut tem preferência absoluta nas lans houses observadas. As "postagens" na rede social referem-se, em grande parte, a comentários e fotos sobre eventos ocorridos com amigos de escola ou da vizinhança, com pessoas com as quais acabou de se ver ou falar de outro modo, reforçando os vínculos já existentes, como transparece no discurso dos informantes; em alguns casos, chega-se a desconfiar da possibilidade de surgimento de uma "amizade verdadeira" no mundo virtual:

\footnotetext{
Não, não gosto [de conhecer gente nova através da Internet]. Não tem necessidade, a gente já conhece tanta gente, pra que que eu vou me dar ao trabalho de tentar conhecer? Porque realmente conhecer a gente não conhece. Você, assim, meio que acredita no que as pessoas estão dizendo, mas você não sabe a verdade como é. Então eu nem entro em sala de bate-papo, eu não gosto muito. (Aline, 19 anos)

O amigo do dia a dia tá comigo, sabe o que eu faço, o que eu não faço, sabe o que eu gosto, sabe o que eu não gosto. Já amigo de Internet não faz nem idéia do que eu gosto do que eu não gosto. (Lucas, 18 anos)
}

A idéia da Internet como lugar do disfarce pode ser ameaçadora para a constituição de relações confiáveis, percepção essa que também surge nas palavras de Francisco, atendente da lan Planeta Conecta:

Eu não adiciono ninguém no MSN se eu não conhecer pessoalmente, eu não gosto. Primeiro que na Internet todo mundo é feliz, né? Então é muita hipocrisia. E minha mãe? Falou que era uma morena linda, não que ela seja feia, mas pela Internet... Tem que ver a foto que ela usa no Orkut, é de outra pessoa, nem sei quem é. Minha mãe já derrubou uns quatro aí, partiu uns quatro corações....

O Orkut é apropriado em várias situações dentro de um sentido de compartilhar com o outro, seja, por exemplo, no caso do vídeo musical preferido de uma adolescente de 14 anos que está no Orkut da mãe, seja no caso da turma de futebol da Associação, cujo presidente, de 47 anos, declara: "São os meninos que mexem no meu Orkut, que fazem tudo, avisam das partidas de futebol, tudo; eu nem sei mexer."

A convivência nos games também alimenta a sociabilidade em outros espaços virtuais, como fica claro no caso de Lúcio, que gosta muito de jogar o Dota - uma 
variação do jogo Warcraft original - tendo criado uma página no Orkut para aficionados como ele. Não gosta da idéia de um ambiente "sem controle", onde poderia entrar gente que ele conhece apenas superficialmente: "Fiz pra fechar, para reunir os amigos, tem que ter gente que eu tenha visto pelo menos uma vez". Esse caso exemplar mostra a primazia da sociabilidade que junta familiaridade e interesses afins - como no Orkut dos "realmente" amigos, cujos limites são controlados, para não se descaracterizar com pessoas não conhecidas, apresentadas por terceiros.

Esse cenário de sociabilidade leva a uma perspectiva que vai de encontro às formulações de Miller e Slater (2004) sobre a inadequação de se fazer uma distinção a priori entre vida on-line e off-line, comum na pesquisa sobre Internet. Os autores, que estudaram as relações vividas em cibercafés de Trinidad, acreditam que essa distinção não deveria ser estabelecida como um ponto de partida metodológico e analítico de pesquisa; ao contrário, a referida distinção é bastante contingencial, já que em alguns contextos as pessoas estabelecem em suas vidas contornos nítidos para cada uma dessas esferas, enquanto que para outras, a distinção não é relevante ou nem chega sequer a ser estabelecida.

Nos ambientes estudados, as relações on-line são fundamentalmente uma extensão da vida off-line, surgindo como uma possibilidade de aprofundar os vínculos já existentes com os pares. Nesse modo, a Internet aparece como um modo de adicionar (Almeida e Eugênio, 2006), de repetir e reforçar o que já foi dito por outros meios - que incluem o contato face a face - junto ao grupo de amigos que constituem a rede de convivência mais familiar e cotidiana da pessoa.

O compartilhamento de um mesmo computador observado anteriormente na experiência do game WoW ocorre também quando várias pessoas na lan se sentam em torno de uma outra que toma a frente da navegação do Orkut. Nesse caso, as que observam dão opiniões sobre que páginas visitar, o que postar e o que "deletar", por exemplo. Em uma destas cenas típicas observadas, uma adolescente navegava ao lado de uma criança e uma mulher mais velha. Esta última fazia pedidos a toda hora - como "ih, tira ele daí, deleta, deleta..." (pedindo para tirar o recado postado por um rapaz). A criança em certo momento sentou no colo da estudante e colocou o fone no ouvido. Depois a mais velha tomou o fone para si e ficou cantando alto a música de um clipe do Youtube, outro site extremamente popular nas lans, enquanto a estudante permanecia à frente do computador, comandando a navegação compartilhada. Por fim, a estudante começa a ler alto um poema de cunho amoroso postado por um rapaz, sendo a leitura 
feita conjuntamente, em voz alta, pela sua acompanhante mais velha. Em outro momento de observação, um grupo de meninas adolescentes entrava no Orkut, procurando atualizar suas páginas e ir na de amigas para ver as novidades. A interação é uma constante durante a navegação - ao mesmo tempo em que se está em frente ao computador, a atenção muda eventualmente de foco para o que as amigas estão fazendo. Nessa experiência coletiva, são sugeridos rumos para a navegação ("vamos entrar no Orkut da minha prima agora") e ações para checar seus relacionamentos ("vou entrar no Orkut dele pra ver se ele tá namorando").

\section{A “favelização do Orkut" e a construção da diferença social na rede}

Pierre Lévy $(1996,2000)$ tem enfatizado o aspecto "democrático" da Internet, como se o espaço virtual, por características intrínsecas, favorecesse o compartilhamento e o igualitarismo, ao provocar alterações drásticas nos modos de pensar, de criar relacionamentos e significados no mundo. A rede surge nesse imaginário como um espaço utópico onde se pode ter acesso a todo tipo de informação e onde os meios de produção de conhecimento e expressões dos mais variados modos estão acessíveis a qualquer pessoa, independente de seu status e condição social. Na vida digital o poder "soberano" e "disciplinar" perderia espaço para um tipo de poder difuso, devido à enorme fragmentação proporcionada pela vivência no ambiente em rede, onde um único elemento tem, potencialmente, a capacidade de influenciar e reconfigurar o todo. Essa inteligência coletiva, que reinaria no espaço "democrático" da Internet, não se trataria apenas de um conceito cognitivo, mas de algo bem mais amplo que envolve a renovação de laços sociais (Lévy, 2000). Na revolução provocada pela rede, os laços sociais são construídos a partir da valorização da diversidade das qualidades humanas. Em uma de suas obras (Lévy, 2000), o filósofo faz referência ao episódio bíblico de Sodoma e Gomorra, destacando que o crime de Gomorra fora a recusa à hospitalidade, que consistiria na marca do relacionamento virtual - reconhecer e acolher o outro:

Ora, a hospitalidade representa eminentemente o sustentáculo do laço social, concebido segundo a forma de reciprocidade: o hóspede é tanto aquele que recebe quanto aquele que é recebido. E cada um deles pode ser tornar estrangeiro (...). A hospitalidade consiste em atar o indivíduo a um coletivo. Contrapõe-se inteiramente ao ato de exclusão. O justo inclui, 'insere', reconstitui o tecido social. Em uma sociedade de justos, e segundo a forma de reciprocidade, cada um trabalha para incluir os outros. [No mundo contemporâneo], onde tudo se move, onde todos são levados a mudar, a hospitalidade, moral dos nômades e migrantes, torna-se moral por excelência. (Lévy, 2000: 36-37) 
A definição a priori de um "novo mundo" de significados que teria se formado a partir do advento das tecnologias digitais é criticável pelo fato de nenhuma tecnologia se instaurar em vazios culturais. Conforme demonstrou Sahlins (1979) em um importante trabalho, não tem sentido se falar em uma dicotomia entre "razão prática" e "razão cultural" já que todo e qualquer ato humano tem uma "intenção cultural". Assim, não se poderia, sob este ponto de vista, se falar em uma "razão tecnológica" que carregasse em si um sentido descolado de experiências culturais concretas.

A partir deste ponto é possível, então, discutir de que modo surgem no universo virtual modos de distinção que reafirmam diferenças sociais presentes no "mundo real", o que se contraporia à idéia da Internet como um espaço propenso à pacífica convivência da diversidade.

A grande disseminação do Orkut junto a segmentos populares acabou por provocar reações de outros grupos que merecem uma reflexão no que diz respeito à questão da vivência da alteridade no ambiente virtual. Em alguns blogs, listas e fóruns, internautas pertencentes às camadas médias e altas começaram a se expressar - muitas vezes de modo bastante explícito e crítico - contra os efeitos do crescente acesso das camadas populares ao mundo digital. Nesse contexto, surgiu a expressão "favelização do Orkut", que fazia uma associação entre "favela", "pobreza" e "mau gosto"; a "invasão" dos pobres brasileiros na Internet, visível especialmente em redes sociais como o Orkut, traria atrás de si um lastro de gosto "brega", expresso nas fotos postadas e no português precário, como aparece em algumas dessas manifestações:

Por que isso? Por que qualquer salsinha que compra um micro na Casa \& Vídeo, em 317 prestações, quer logo entrar na Internet e faz um perfil no Orkut?

O Orkut já prestou. Hoje em dia está infestado de pessoas com Mobral Incompleto de escolaridade. Todos querem ser sensuais. Todos querem ser famosos. Pior que todos procriam...

Mas há uma saída! Há uma luz no fim do túnel.

Bagulho Digital lança a campanha DIGA NÃO À FAVELIZAÇÃO ELETRÔNICA. (http://bagulhodigital.blogspot.com/2007/09/favela-eletrnica.html)

Sabe, brasileiro ainda é novo com esse lance de internet, e infelizmente transportou a mediocridade da vida para o Orkut. Ou seja, brasileiro favelou o Orkut. Favelou mesmo, esse é o termo. E não foi só o Orkut... o Fotolog.net ERA o melhor sistema online de fotos. Era! Até ser descoberto por brasileiros. (http://www.morroida.com.br/2006/08/28/sobre-o-orkut)

Grande parte da descaracterização do Orkut, deve-se a tão falada "inclusão digital". Graças à Casas Bahias e Insinuantes da vida, conseguimos comprar PC's por R\$ 700,00. Em comunidades carentes pipocam Lan Houses que cobram ente 1 e 2 Reais a hora. Sendo assim, os privados de educação não estão mais privados de tecnologia. Portanto temos o mais novo problema sócio-político-econômico: A FAVELIZAÇÃO DO ORKUT! 
(http://metabolismobasal.blogspot.com/2007/12/lembra-do-longnquo-ano-de-2004lembra.html)

Se isso já aconteceu com orkut e fotolog, deixa só a favelada descobrir o youtube... se é que já não descobriram... sem querer ser separatista, mas já sendo, é foda ter que conviver com certas sub-culturas que vêm surgindo na internet tupiniquim... (http://www.morroida.com.br/2006/08/28/sobre-o-orkut/)

Ao lado das citadas manifestações, os internautas colocavam fotos consideradas "toscas", garimpadas no Orkut e em fotologs de pessoas de baixa renda, para ilustrar sua “indignação”. Chama atenção aqui o reforço das representações negativas associadas à "favela" entre os membros das camadas médias e altas. Como local habitualmente associado à extrema pobreza, sujeira, caos e desordem social (Valladares, 2005), a idéia de "favelização" na rede atualiza antigas percepções. No segundo dos depoimentos acima, inclusive, o próprio país aparece como uma grande favela; trata-se da concepção de que os brasileiros "contaminam" os ambientes - reais ou virtuais - por onde transitam, enquanto povo "desqualificado" frente a outras nacionalidades.

A "indesejada" inclusão digital faz com que certos grupos economicamente mais favorecidos rejeitem o Orkut, alegando a impossibilidade de conviver no mesmo espaço virtual com manifestações de "falta de gosto" e "educação" formal vindas da "periferia”. Surge, então, a necessidade de "distinção", que tem levado a um movimento migratório para redes sociais mais elitizadas como o Facebook, especialmente.

A análise da relação entre consumo e classes sociais teve uma importante contribuição na obra de Bourdieu (1979) em seu clássico La Distinction, onde o autor analisa como se constitui a elaboração social do gosto, argumentando que as escolhas de objetos de consumo refletem uma espécie de hierarquia simbólica determinada e mantida pelas classes economicamente superiores para reforçar sua distinção de outras classes sociais. O gosto, então, seria um elemento que define e separa a classe alta das camadas trabalhadoras, se expressando nas escolhas de comida, bebida, cosméticos, música, literatura, etc.. Aparecendo na vida social de modo naturalizado, torna-se o critério legitimidador de distinções por excelência, abrangendo todas as dimensões da vida humana que incluem a escolha e dessa forma, constituindo grupos sociais.

As expressões contra a inclusão digital recolhidas na pesquisa mostram a necessidade de distinção de certos indivíduos das camadas médias e altas frente à aproximação e ocupação dos grupos populares em territórios antes quase que exclusivos. Como mostra Bourdieu (1979), acusações sobre o (mau) gosto de pessoas de baixa renda são como uma "arma" social que distingüe grupos a partir de um 
processo de desqualificação social que aparece de maneira extremamente naturalizada. O material virtual referente à "favelização do Orkut" mostra fotos que denunciariam uma estética onde os "toscos" e "bregas" exibem tanto o "mau gosto" de roupas e acessórios, quanto seus corpos inadequados. com comentários críticos ao peso excessivo e cabelos de jovens de baixa renda, por exemplo. Deveriam, assim, permanecer em espaços restritos - e o Orkut seria um desses locais - surgindo a necessidade, por parte dos descontentes com a proximidade virtual, de deslocamento para outros domínios.

O "potencial democrático" da rede é vivido nesse contexto como uma grande ameaça para certos membros das classes médias e altas. Lembrando mais uma vez de Douglas e Isherwood (1979), se o consumo serve como "pontes ou barreiras", se ergue aqui um "muro" digital a partir da crescente participação de grupos populares em redes sociais como o Orkut. Boyd (2008) já havia analisado, em um estudo, de que modo as opções entre internautas norte-americanos pelas redes sociais MySpace, mais popular, ou Facebook, "aristocrática", podiam revelar escolhas de classes buscando a diferenciação.

Vale lembrar nesse ponto a análise de DaMatta (2000) sobre modos de segregação no Brasil e nos Estados Unidos. Ao falar da questão racial, propõe que, entre os norte-americanos, o modelo adotado seja o "iguais, mas diferentes", pois trata-se de uma sociedade que tem princípios igualitários por base e que, por isso, acaba criando modos de segregação bastante explícitos e excludentes; o caso brasileiro, por sua vez, poderia ser traduzido pela idéia de "diferentes, mas iguais", já que a sociedade é percebida como originariamente hierárquica, o que permitiria a aproximação das partes contanto que cada um não esquecesse a sua origem diferenciada:

Um sistema de fato profundamente antiigualitário, baseado na lógica do 'um lugar para cada coisa, cada coisa em seu lugar', que faz parte da nossa herança portuguesa, mas que nunca foi realmente sacudido pelas transformações sociais. De fato, um sistema tão internalizado que, entre nós, passa despercebido" (DaMatta, 2000: 83).

Por um lado, a sociedade brasileira gosta de se pensar como uma nação inclusiva, em que as diferenças convivem de modo harmônico, como no mito do triângulo das três raças (DaMatta, 2000). Por outro, em diversos momentos surgem rupturas nesse esquema, dando espaço ao aparecimento de ritos autoritários como o "Você sabe com quem está falando?", que reinstauram a hierarquia entre os indivíduos, ou como no caso dos dados levantados pela pesquisa, em que os espaços, estilos de vida 
e gostos são demarcados de maneira bastante explícita. O "perigo" da Internet estaria exatamente na possibilidade de extrema aproximação das diferenças sociais; os argumentos surgidos na idéia de "favelização do Orkut" apelam para princípios hierárquicos naturalizados e longamente enraizados na sociedade brasileira, solicitando aos grupos populares que se mantenham em seus espaços restritos - agora virtuais dentro da lógica do "cada um em seu lugar".

\section{Considerações finais}

$\mathrm{O}$ artigo procurou compreender alguns sentidos da navegação na Internet a partir de um olhar nas interações encontradas no espaço da lan e no contexto cultural dos atores sociais investigados. As práticas ligadas ao meio computador revelam diversos aspectos do universo social estudado, como a apropriação dos espaços das lan houses como um clube local e as práticas de navegações compartilhadas. A relativização do modo de consumo "individual" se faz necessária para a compreensão da construção da subjetividade e dos usos coletivos relacionado à tecnologia computador, o que se evidencia particularmente na experiência com os games e navegações em redes sociais.

As navegações coletivas nos games e na rede social do Orkut reforçam vínculos sociais familiares e cotidianos, não se constatando aqui qualquer tipo de esvaziamento das relações da "vida real". Isso não expressa, necessariamente, uma aversão a novos contatos na Internet, mas sim uma clara ênfase na alimentação e reforço da rede de sociabilidade já constituída, o que leva a um questionamento de oposições a priori entre relacionamento "virtual" e "real" (Miller e Slater, 2000). O que foi possível observar, de fato, foi um reforço dos vínculos na experiência da rede social, com um forte apelo para a localidade. Falar com quem "se conhece", com quem "se vê todo dia", com quem "acabou de se falar ou ver", parecem ser as grandes motivações da sociabilidade constituída entre os informantes, que tem, por isso, a marca da familiaridade. No discurso dos informantes, evidenciou-se certa percepção da Internet como um espaço ambígüo, potencialmente enganoso quando envolve contatos que partem do anonimato e onde o estabelecimento de relações "verdadeiras" seria pouco provável; trata-se da idéia da Internet como o lugar privilegiado para o disfarce e a dissimulação. Diversos estudos antropológicos (em especial, Duarte, 1986; Sarti, 1996; Fonseca, 2004) voltados para o universo das camadas populares destacam três pontos de referência central em sua visão de mundo: família, trabalho e localidade. De certo modo, os dados etnográficos aqui apresentados refletem os valores tradicionalmente encontrados nestes 
contextos culturais - uma ênfase nas relações estabelecidas sob a marca da familiaridade e da localidade e certa desconfiança de relações iniciadas fora deste círculo, sem mediações, como é o caso do universo virtual.

O tema da "favelização do Orkut" serve a uma reflexão sobre como a alteridade pode ser vivida no universo virtual. Como visto a reprodução de consolidados modos de segregação e desqualificação direcionados aos grupos populares acaba por colocar em cheque o imaginário da Internet como espaço "democrático", "participativo" e "humanitário" - neste último aspecto, pela idéia de que permitiria uma ampla expressão dos interesses das minorias - por excelência (Lévy, 1999). Como já chamaram atenção Maigret (2010) e Wolton (2003), é necessário se fugir do determinismo tecnológico que ronda parte da literatura sobre a Internet, dando um foco maior às práticas culturais que no uso desta tecnologia as precedem, criando configurações particulares.

\section{Referências}

BARROS, Carla. "Sociabilidade e alteridade nos usos de tecnologias digitais no universo das camadas populares". Anais da VIII Reunião de Antropologia do Mercosul, RAM 2009. Buenos Aires, Argentina, 2009.

BIRMAN, Patrícia. "Favela é Comunidade?" In: SILVA, Luiz Antônio M (Org). Vida sob cerco: Violência e rotina nas favelas do Rio de Janeiro. Rio de Janeiro: Nova Fronteira, 2008.

BOURDIEU, Pierre. La distinction: Critique sociale du jugement. Paris: Minuit, 1979.

BOYD, Danah. Viewing American class divisions through Facebook and MySpace. Disponível em: http://www.danah.org/papers/essays/ClassDivisions.html. Último acesso: 15 set 2008.

DOUGLAS, Mary; ISHERWOOD, Baron. The world of goods: towards an anthropology of consumption. Middlesex: Penguin, 1979.

DUARTE, Luiz Fernando D. Da vida nervosa (nas classes trabalhadoras urbanas). Rio de Janeiro: Zahar Ed., 1986.

FONSECA, Cláudia. Família, fofoca e honra. Porto Alegre: Ed. UFRGS, 2004.

GOMES, Laura G. "Fansites ou o 'consumo da experiência' na mídia contemporânea". In: Revista Horizontes Antropológicos, ano 13, n. 28, jul./dez. Porto Alegre: PPGAS UFRGS, 2007. p. 313-344.

LÈVY, Pierre. Cibercultura. São Paulo: Ed. 34, 1999.

LÈVY, Pierre. A inteligência coletiva: Por uma antropologia do ciberespaço. $3^{\mathrm{a}}$ ed. São Paulo: Loyola, 2000.

LEVY, Pierre. O que é o virtual? São Paulo: Ed. 34, 1996.

MAIGRET, Éric. Sociologia da comunicação e das mídias. São Paulo: Ed. Senac São Paulo, 2010.

MILLER, Daniel; SLATER, Don. "Etnografia on e off-line: cibercafés em Trinidad". In: Revista Horizontes antropológicos, ano 10, $\mathrm{n}^{\mathrm{o}} 21$, jan/jun. Porto Alegre: PPGAS UFRGS, 2004. p. 41-65. 
MILLER, Daniel; SLATER, Don. The Internet: An ethnographic approach. Oxford: Berg, 2000.

SARTI, Cynthia. A família como espelho: um estudo sobre a moral dos pobres. Campinas: Ed. Autores Associados, 1996.

SIMMEL, Georg. "Sociabilidade: um exemplo de sociologia pura ou formal". In: MORAES FILHO, Evaristo (org). Simmel. São Paulo: Ática, 1983.

SPENCE, Jeremiah. "Orkut: a catalysis for the Brazilian internaut". AoIR 8.0: Association of Internet Researchers International Conference. Vancouver, Canada. October 2007.

VALLADARES, Lícia. A invenção da favela: do mito de origem a favela.com. Rio de Janeiro: FGV, 2005.

WOLTON, Dominique. Internet, e depois? Uma teoria crítica das novas mídias. Porto Alegre: Sulina, 2003. 